\title{
Basketball Shoe Height and the Maximal Muscular Resistance to Applied Ankle Inversion and Eversion Moments*
}

\author{
Robert A. Ottaviani, $†$ James A. Ashton-Miller, $\ddagger$ PhD, Sandip U. Kothari, $†$ and \\ Edward M. Wojtys, †§ MD
}

\begin{abstract}
From †MedSport, Section of Orthopaedic Surgery, and the $¥ D$ Department of Mechanical Engineering at the University of Michigan, Ann Arbor, Michigan
\end{abstract}

\begin{abstract}
To determine if the height of a basketball shoe alters the maximal inversion and eversion moment that can be actively resisted by the ankle in the frontal plane, we tested 20 healthy, young adult men with no recent ankle injuries. Subjects underwent unipedal functional ankle strength testing under weightbearing conditions at $0^{\circ}$, $16^{\circ}$, and $32^{\circ}$ of ankle plantar flexion using a specially designed testing apparatus. Testing was performed with the subject wearing either a low- or a three quartertop basketball shoe. Shoe height did not significantly affect an individual's ability to actively resist an eversion moment at any angle of ankle plantar flexion. However, tests at $0^{\circ}$ of ankle plantar flexion demonstrated that the three quarter-top basketball shoe we tested significantly increased the maximal resistance to an inversion moment by $29.4 \%$. At $16^{\circ}$ of ankle plantar flexion, inversion resistance was also significantly improved by $20.4 \%$. These results show that athletic shoe height can significantly increase the active resistance to an inversion moment in moderate ankle plantar flexion. The findings apply to a neutral foot position in the frontal plane, an orientation equivalent to the early phase of a potential ankle sprain.
\end{abstract}

Ankle inversion injuries are among the most common in sports, accounting for up to $25 \%$ of all time lost from competition. ${ }^{15,23}$ The ankle's susceptibility to injury appears to be related to ankle and foot positioning. With increasing ankle plantar flexion, the orientation of the anterior talo-

\footnotetext{
*Presented at the 20th annual meeting of the AOSSM, Palm Desert, California, June 1994

\$Address correspondence and reprint requests to Edward $\mathrm{M}$. Wojtys, MD MedSport, 24 Frank Lloyd Wright Drive, POB 363, Ann Arbor, Mł 48106.

No author or related institution has received any financial benefit from a product named or used in this study. See "Acknowledgments" for funding information.
}

fibular ligament progressively becomes less advantageous ${ }^{16}$ and may increase the risk of injury. Many sports require the ankle-foot complex to adapt continually to changes in muscular loading, variations in ground surface and compliance, and changes in external forces and moments. Passive resistance to deforming forces that can lead to ankle injury under these conditions is normally provided by passive soft tissue elements at a rate of $0.24 \mathrm{~N}-\mathrm{m} / \mathrm{deg} .{ }^{3}$

In neutral or ankle plantar flexed positions, the peroneal muscles are primarily responsible for providing active resistance to externally induced inversion moments. If talocalcaneal rotation relative to the tibia goes unchecked during ankle inversion, anterior talofibular and calcaneofibular ligament injury or rupture can be expected, with subsequent bony injury if the external forces continue. The effectiveness of active resistance to inversion moments at increasing degrees of ankle plantar flexion in uninjured ankles is addressed in this study.

High-top athletic shoes are frequently chosen to augment ankle support because they may provide increased resistance to ankle rotation in the frontal plane. ${ }^{29}$ The increasing cost of these shoes may be justified if they decrease ankle injury rates, ${ }^{10}$ although not all studies support this finding. ${ }^{1}$ The lack of concordance on this issue may be partly explained by the fact that in the neutral ankle position in the frontal plane these devices probably offer little or no passive resistance to a ground-reaction force acting to invert the ankle. It is only as ankle inversion increases from the neutral position that passive shoe resistance rises. If the external moment increases at a faster rate than that of the passive resistance of the shoe, ankle passive tissues, and active resistance from muscle activity, then a large increase in inversion rotation can occur as a result of a small increase in moment. This would be an example of mechanical instability and could result in soft tissue or bony injury. A primary focus of this study was to determine the level of resistance offered by a three quarter-top basketball shoe early in this sequence of events, when the ankle joint is close to its neutral position in the frontal plane. 
Recently, Gilsing et al. ${ }^{11}$ showed that the proprioceptive threshold for detecting ankle inversion rotation is better than $0.1^{\circ}$ in the young, healthy, weightbearing adult ankle. Therefore, for practical purposes, most inversion rotations are detectable by the human sensorimotor system. When the ankle-foot complex is loaded by an inversion moment, the only resistance that can be developed without a time delay is that provided passively by bone, soft tissue, or shoes. Peroneal muscle and tendon stiffness can play a role in ankle protection only when the peroneal muscles are already activated. Unfortunately, active peroneal muscle responses are delayed by neuromuscular latencies, perhaps crucially so in some cases.

The goals of this investigation were to 1) test the hypothesis that no significant difference exists between low and three quarter-top basketball shoes in their ability to supplement active resistance to inversion and eversion moments with the ankle in a neutral position, 2) test the hypothesis that this resistance is not significantly affected by increasing the angle of ankle plantar flexion, 3) determine the maximal active resistance to applied inversion and eversion moments in healthy young males using two different measurement techniques, and 4) examine the correlation between unipedal strength values, isokinetic strength, isokinetic time to peak torque, physical activity, and calf size.

\section{MATERIALS AND METHODS}

\section{Subjects}

Twenty healthy, young adult men (mean age, $22.6 \pm 3.1$ years) with no ankle injuries in the 6 months before testing were recruited for testing. Leg dominance (defined by which leg they preferred to kick a ball with), hand dominance, maximal calf circumference, height, weight, and physical activity level were recorded (Table 1).

\section{Range of Motion}

Each participant's active range of dorsiflexion, plantar flexion, inversion, and eversion were measured using a goniometer. Dorsiflexion and plantar flexion were measured with the participant seated and his knee and ankle in $90^{\circ}$ of flexion. Inversion and eversion motion were measured with the subjects lying in the prone position. Three reference points, positioned in a straight line, were used to identify the neutral position of the foot relative to the leg in the

TABLE 1

Patient data

\begin{tabular}{lrrc}
\hline \multicolumn{1}{c}{ Variable } & Mean & SD & Range \\
\hline Weight $(\mathrm{kg})$ & 77.2 & 10.7 & $63.5-104.3$ \\
Height $(\mathrm{cm})$ & 179.8 & 5.8 & $170.2-188.0$ \\
Calf circumference (cm) & 37.8 & 2.4 & $33.5-42.7$ \\
Activity level $^{a}$ & 6.6 & 1.4 & $4-10$ \\
\hline
\end{tabular}

${ }^{a} 10=$ Competitive jumping, turning, twisting sports; $8=$ Recreational jumping, turning, twisting sports; $6=\mathrm{Jog}$, bike, swim, occasional pivoting sports; $4=$ No jumping, turning, twisting sports; jog, bike, swim regularly; $2=$ No jumping, turning, twisting sports; occasional jog, bike, swim; $0=$ Sedentary. frontal plane. The first point was centered on the middle of the calf, the second on the distal portion of the Achilles tendon, and the third over the center of the calcaneus. Calf circumference was measured at a point one third the distance from the fibular head to the lateral malleolus with the knee at $90^{\circ}$ of flexion and the muscles relaxed.

\section{Isokinetic Dynamometer}

Ankle strength, in dorsiflexion and plantar flexion and in inversion and eversion, was tested and recorded using an isokinetic dynamometer (Biodex, Biodex Corp., Shirley, New York). Each subject was seated at the dynamometer with his knee flexed $15^{\circ}$ during testing. After a warmup, each participant performed three repetitions at $60 \mathrm{deg} /$ sec for each test. Performance always improved after the first test, so the first trial of each test was discarded. Verbal encouragement and visual feedback of results were given to obtain maximal effort. Maximal peak torques, time to peak torque, and maximal ranges of motion (dorsiflexion, plantar flexion, inversion, and eversion) were recorded.

\section{Unipedal Strength Test}

The strength of the right ankle of each subject was tested under unipedal weightbearing conditions at $0^{\circ}, 16^{\circ}$, and $32^{\circ}$ of plantar flexion using a specially designed testing apparatus $^{32}$ (Fig. 1). The testing apparatus consisted of a

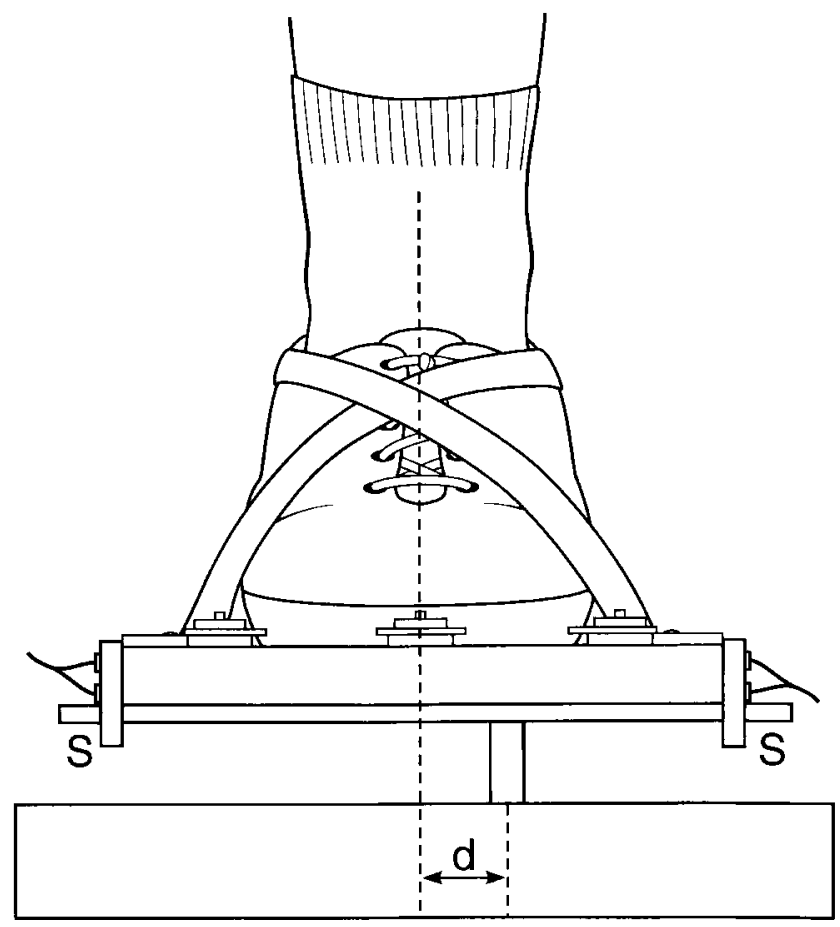

Figure 1. Schematic of the testing device used for the unipedal strength test with the low-top shoe. Contact switches (S) indicate tilts greater than $5^{\circ}$. $d$ is the moment arm of the center of the ground reaction force acting upward through the peg about the ankle joint center. 
shoe securely fastened to a $1.5-\mathrm{cm}$ thick, 36 by $20 \mathrm{~cm}$ board with a track accommodating a $40-\mathrm{cm}$ long, 5 by $10 \mathrm{~mm}$ steel bar. This track was positioned transversely at the level of the fifth metatarsophalangeal joint. A centimeter scale was located on top of the steel bar, and the bottom of the bar had a 13-mm diameter circular recess to accommodate the top end of a 3-cm long, 12.5-mm diameter vertical fixed peg screwed firmly into a large steel base plate. For the subject to stand on the peg with the bar horizontal required sustained inversion or eversion ankle moments depending on the relative locations of the peg and mechanical center of the ankle. A microswitch was attached to each corner of the board as part of a circuit to detect changes in the horizontal position of more than $5^{\circ}$.

After the bar was positioned in the track under the area of the fifth metatarsophalangeal joint, each participant placed his right foot in the shoe of the apparatus and was asked to tighten the laces as tightly as possible without causing discomfort. The steel peg was initially positioned $7 \mathrm{~cm}$ lateral to the mechanical center of the ankle joint in the frontal plane, which was defined by locating the midpoint between the two malleoli. Participants were asked to balance unipedally on the device for a minimum of 2 seconds. A support bar was used until the subject became balanced, then finger support was removed and the subject attempted to maintain the level position $\left( \pm 5^{\circ}\right)$ for 2 seconds. The test began when the participant released the support bar and ended when the circuit light indicated a deviation greater than $5^{\circ}$ or when any part of the subject touched the ground or support bar. Maintenance of a level position for 2 seconds was considered a successful test. Failure to balance the device for 2 seconds was an unsuccessful test. Three trials were allowed. The steel peg was moved in $1 \mathrm{~cm}$ increments toward the center of the ankle until a successful trial was completed.

After the first successful trial, adjustments of $0.25 \mathrm{~cm}$ were made in the lateral peg direction until the most lateral peg position successfully tolerated was identified. This position was used to determine the final peg distance from the ankle joint center. This distance was used to estimate inversion strength using the following formula:

Moment $(\mathrm{N}-\mathrm{m})=$ Body weight $(\mathrm{N}) \times$ Maximal distance $(\mathrm{m})$

The same procedure was used to determine eversion strength by starting $7 \mathrm{~cm}$ medial to the center of the ankle joint in the frontal plane. All tests in inversion and eversion were repeated with a $16^{\circ}$ and a $32^{\circ}$ wedge under the posterior two thirds of the foot to determine the effect of plantar flexion on ankle strength.

All tests were performed using Nike Air Force I low-top and the Air Force Max three quarter-top basketball shoes (Nike, Inc., Beaverton, Oregon). The sequence for testing in the low- and three quarter-top shoes, at the three positions $\left(0^{\circ}, 16^{\circ}, 32^{\circ}\right.$ of ankle plantar flexion) was randomly determined and varied among subjects. Because of its design, the low-top shoe could offer no passive resistance to inversion or eversion and so acted as a control for the three quarter-top shoe tests.

\section{Repeatability}

Repeatability testing was performed on three subjects for both the dynamometer strength measurements and the dynamic strength test. Plantar flexion, dorsiflexion, inversion, and eversion strengths were measured to establish test variability among measurements within a day and also among three measurements on different days. The magnitude of the expected measurement variability was expressed by computing $95 \%$ confidence limits. These limits were used to establish statistical significance.

\section{Statistical Analyses}

Descriptive statistics were calculated for all variables. A repeated measures analysis of variance (rm-ANOVA) was used to test the null hypothesis that shoe height (low- or three quarter-top) had no effect on the magnitude of the external ankle moment that could be resisted in inversion or eversion at three different angles of ankle plantar flexion $\left(0^{\circ}, 16^{\circ}, 32^{\circ}\right)$. Post hoc, two-sided, paired Student's $t$-tests were used to test the magnitude and direction of any main effects using a $P$ value of 0.05 . Paired Student's $t$-tests were also used to examine differences among moments developed at the different angles of ankle plantar flexion.

\section{RESULTS}

\section{Repeatability}

The 95\% confidence levels obtained for the isokinetic dynamometer were $\pm 8.94, \pm 3.22, \pm 3.89$, and $\pm 1.20 \mathrm{~N}$-m in plantar flexion, dorsiflexion, inversion, and eversion, respectively. The $95 \%$ confidence levels for the unipedal eversion test were $\pm 1.51, \pm 1.78$, and $\pm 1.91 \mathrm{~N}$-m at $0^{\circ}, 16^{\circ}$, and $32^{\circ}$ ankle plantar flexion, respectively. Similarly, the corresponding values for the unipedal inversion strengths at $0^{\circ}, 16^{\circ}$, and $32^{\circ}$ of ankle plantar flexion were $\pm 2.83, \pm 1.43$, and $\pm 2.63 \mathrm{~N}-\mathrm{m}$, respectively.

\section{Range of Motion}

The mean (SD) ranges of motion in dorsiflexion, plantar flexion, eversion, and inversion were $14.5^{\circ}\left(4.7^{\circ}\right), 53.6^{\circ}$ $\left(7.0^{\circ}\right), 10.4^{\circ}\left(3.2^{\circ}\right)$, and $17.3^{\circ}\left(7.5^{\circ}\right)$, respectively. These values show that no subject was tested near his maximal range of motion. Nineteen of the 20 participants reported right leg dominance and none of the participants reported ankle sprains within the last year.

\section{Unipedal Strength Test}

In testing the two primary hypotheses, the mean resistance to inversion increased with ankle plantar flexion (rmANOVA, $P=0.062$ ) and was significantly larger in the three quarter-top shoe than in the low-top shoe (rmANOVA, $P<0.001$ ). The following paragraphs describe these differences in detail. 


\section{Low-Top Shoe}

Resistance to Inversion Moment (Eversion Strength). The 20 participants were best able to actively resist an external inversion moment at the ankle with the foot plantar flexed at $32^{\circ}$. They had $17.5 \%$ greater eversion strength at $32^{\circ}$ of ankle plantar flexion than at $0^{\circ}$ of ankle plantar flexion (Table 2). The least resistance to an external inversion moment was developed at $0^{\circ}$ of ankle plantar flexion (Table 2 ). The results of the paired Student's $t$-tests showed that the differences in resistance were significant between $0^{\circ}$ and $16^{\circ}(P=0.049)$ and between $0^{\circ}$ and $32^{\circ}(P=0.049)$ of ankle plantar flexion; the difference between $16^{\circ}$ and $32^{\circ}$ of ankle plantar flexion was not significant.

Resistance to Eversion Moment (Inversion Strength). The active inversion strength needed to equilibrate an eversion moment was greatest with the foot at $0^{\circ}$ and second greatest at $16^{\circ}$. The least resistance to an eversion moment occurred with the foot in $32^{\circ}$ of ankle plantar flexion (Table 2 ). The difference in the ability to resist an eversion moment was significant between $0^{\circ}$ and $32^{\circ}$ of ankle plantar flexion $(P=0.026)$. The differences between $0^{\circ}$ and $16^{\circ}$ and $16^{\circ}$ and $32^{\circ}$ of ankle plantar flexion were not significant.

\section{Three Quarter-Top Shoe}

Resistance to Inversion Moment (Eversion Strength). The minor differences in the active resistance to an inversion moment at $0^{\circ}, 16^{\circ}$, or $32^{\circ}$ of ankle plantar flexion were not statistically significant (Table 2).

Resistance to Eversion Moment (Inversion Strength). The active resistance to an eversion moment was the greatest at $0^{\circ}$ of ankle plantar flexion, and the least resistance to an eversion moment occurred when the foot was in $32^{\circ}$ of ankle plantar flexion (Table 2 ). The difference in ankle resistance between $0^{\circ}$ and $16^{\circ}$ of ankle plantar flexion was not significant. However, the difference was significant between $0^{\circ}$ and $32^{\circ}(P=0.005)$ of ankle plantar flexion and between $16^{\circ}$ and $32^{\circ}(P=0.048)$ of ankle plantar flexion.

\section{Shoe Comparison}

Resistance to Inversion Moment (Eversion Strength). The active resistance generated in response to an inversion moment with the three quarter-top shoe was significantly larger $(29.4 \%, P<0.001)$ than with the low-top shoe when the foot was at $0^{\circ}$ of ankle plantar flexion. At $16^{\circ}$ of ankle plantar flexion, the three quarter-top shoe significantly increased the resistance to an inversion moment by $20.4 \%$ ( $P=0.003$ ). At $32^{\circ}$ of ankle plantar flexion, the advantage of the three quarter-top shoe was decreased to $11 \%$, which was no longer a statistically significant difference (Table 3).

Resistance to Eversion Moment (Inversion Strength). At $0^{\circ}$ of ankle plantar flexion, the three quarter-top shoe decreased the resistance to an eversion moment by $6.8 \%$ compared with the low-top shoe. At $16^{\circ}$ and $32^{\circ}$ of ankle plantar flexion, the three quarter-top shoes provided a negligible increase in active resistance to an eversion moment. For all three positions, the differences between the three quarterand the low-top shoes were not significant (Table 3).

\section{Comparison of Maximal Unipedal and Isokinetic Strengths (Low-Top Only)}

The mean maximal isokinetic inversion torque generated (Table 4) was $59 \%$ of the maximal inversion strength developed during the weightbearing unipedal strength test at $0^{\circ}$ of ankle plantar flexion. The corresponding difference in eversion was $80 \%$. Time to develop peak torques in eversion was $51 \%$ longer than the time required to generate peak inversion torques.

\section{Other Results}

A linear regression analysis of calf circumference, isokinetic peak torque (in dorsiflexion, plantar flexion, inversion, and eversion), isokinetic time to peak torque, and activity level compared with performance in the weightbearing unipedal strength test showed no significant correlations.

\section{DISCUSSION}

The results of this investigation indicate that, even with a neutral ankle angle in the frontal plane, participants could generate up to $29.4 \%$ greater resistance to ankle inversion with a firmly laced three quarter-top shoe than with a lowtop shoe. This is consistent with the findings of Shapiro et al. ${ }^{29}$ based on static ankle testing in cadavers that demonstrated a significant increase in passive ankle resistance to inversion moments when a high-top shoe was worn. By examining the foot-ankle complex at or near a neutral ankle angle in the frontal plane, we sought to determine

TABLE 2

Mean (SD) maximal inversion and eversion moments (in newton-meters) actively generated in the low-top and three quarter-top shoes in the unipedal stance

\begin{tabular}{lccr}
\hline \multicolumn{1}{c}{ Shoe } & \multicolumn{3}{c}{ Plantar flexion angle } \\
\cline { 2 - 4 } & \multicolumn{1}{c}{$0^{\circ}$} & $16^{\circ}$ \\
\hline Low-top & & & \\
$\quad$ Eversion moment developed & $21.87(9.25)$ & $23.97(9.03)$ & $32^{\circ}$ \\
$\quad$ Inversion moment developed & $38.87(15.13)$ & $34.68(14.01)$ & $25.70(10.27)$ \\
Three quarter-top & & $28.86(8.48)$ & \\
$\quad$ Eversion moment developed & $28.30(9.36)$ & $35.17(12.16)$ & $28.52(7.64)$ \\
$\quad$ Inversion moment developed & $36.24(14.01)$ & $32.60(14.80)$ \\
\hline
\end{tabular}


TABLE 3

Mean (SD) moment differences (in newton-meters) in moments developed in the three quarter-top and low-top shoes at the different degrees of plantar flexion ${ }^{a}$

\begin{tabular}{|c|c|c|c|c|}
\hline \multicolumn{3}{|c|}{ Variable } & & \\
\hline \multicolumn{4}{|c|}{$\begin{array}{l}\text { Resistance to inversion moments } \\
\text { Resistance to eversion moments }\end{array}$} & $\begin{array}{r}6.42(4 \\
-2.63(8\end{array}$ \\
\hline \multicolumn{5}{|c|}{$\begin{array}{l}{ }^{a} \text { Values expressed as three quarter-top minus low-top values. } \\
{ }^{b} \text { Significant at the } 0.05 \text { level. }\end{array}$} \\
\hline \multicolumn{5}{|c|}{$\begin{array}{c}\text { TABLE } 4 \\
\text { Isokinetic peak torque (in newton-meters) and } \\
\text { time to peak torque (TPT) }\end{array}$} \\
\hline Position & & Mean & SD & Range \\
\hline Dorsiflexion & $\begin{array}{l}\text { Peak torque } \\
\text { TPT (msec) }\end{array}$ & $\begin{array}{l}16.73 \\
322.3\end{array}$ & $\begin{array}{l}6.85 \\
137.3\end{array}$ & $\begin{array}{r}7.0-28.7 \\
156-639\end{array}$ \\
\hline Plantar flexion & $\begin{array}{l}\text { Peak torque } \\
\text { TPT (msec) }\end{array}$ & $\begin{array}{l}88.60 \\
267.6\end{array}$ & $\begin{array}{l}13.84 \\
42.6\end{array}$ & $\begin{array}{l}62.9-110.1 \\
172-377\end{array}$ \\
\hline Eversion & $\begin{array}{l}\text { Peak torque } \\
\text { TPT (msec) }\end{array}$ & $\begin{array}{l}13.00 \\
380.1\end{array}$ & $\begin{array}{l}2.81 \\
195.9\end{array}$ & $\begin{array}{l}6.9-17.6 \\
123-762\end{array}$ \\
\hline Inversion & $\begin{array}{l}\text { Peak torque } \\
\text { TPT (msec) }\end{array}$ & $\begin{array}{l}31.20 \\
251.2\end{array}$ & $\begin{array}{l}7.94 \\
126.5\end{array}$ & $\begin{array}{c}17.1-46.1 \\
156-737\end{array}$ \\
\hline
\end{tabular}

how much subtalar moment resistance can be developed in the early phase of a potential ankle sprain.

Although this project focused on the neutral ankle position in the frontal plane, further work is needed at the limits of inversion and eversion as well as determining the effects of the three quarter-top shoe on ankle behavior in women. The three quarter-top shoe resistance, averaging about $28 \mathrm{~N}-\mathrm{m}$ (Table 2), can be expected to increase with increasing ankle inversion angle. Ankle resistance to inversion moments was also found to increase by up to $17.5 \%$ with increasing ankle plantar flexion in the low-top shoe. This is significant because ankle plantar flexion is often present during initial ground contact in many running, jumping, turning, and twisting activities. Interestingly, the resistance to inversion and eversion moments generated during unipedal strength testing under weightbearing conditions did not correlate with isokinetic ankle strength or isokinetic time to peak torque measured in a nonweightbearing posture, or to physical activity level or calf size. Although calf size and isokinetic muscle strength are considered relative indicators of muscle development, they apparently did not necessarily reflect the unipedal strength. In addition, muscle strength can only protect the ankle if timely muscle activation is achieved. Therefore, neuromuscular response time would appear to be an important clinical parameter. Unfortunately, this was not addressed in this study.

The response of the peroneal muscles to sudden ankle inversion has been measured experimentally under various conditions. ${ }^{17,21,25,30}$ The average latency for a peroneal muscle EMG response to forced inversion was found to be 69 msec. ${ }^{21}$ The dynamic elastic resistance of the passive unsupported ankle during a sudden large inversion rotation lasting $40 \mathrm{msec}$ has been estimated at $0.9 \mathrm{~N}-\mathrm{m} / \mathrm{deg}{ }^{25}$ At the limit of the range of inversion rotation $\left(17^{\circ}\right)$, this amounts to no more than $15 \mathrm{~N}-\mathrm{m}$ of resistance, or less than half the maximal static loading $(38 \mathrm{~N}-\mathrm{m})$ we have shown can be resisted statically in inversion (Table 2). This resistance is one third the $57 \mathrm{~N}-\mathrm{m}$ that might be applied dynamically if the same ground reaction is assumed to increase by $50 \%$ of body weight when landing during running or jumping activities. ${ }^{33}$ After ankle muscle activation is detected by EMG, it should be noted that considerable time is taken to develop even half of the maximal strength at the ankle: $92 \mathrm{msec}$ in the dorsiflexor muscles and $133 \mathrm{msec}$ in the plantar flexor muscles. ${ }^{31}$ This is confirmed by the present data (Table 4), which show several hundred milliseconds are required to generate peak torques. Thus, without shoe or orthotic support laced appropriately or preactivation of the peroneal muscles, the ankle is vulnerable to an inversion injury for several hundred milliseconds, or for considerably longer than is indicated by only recording the onset of the peroneal muscles on EMG.

The fact that isokinetic eversion strength at $60 \mathrm{deg} / \mathrm{sec}$ was $40.6 \%$ less than the quasistatic measure obtained using the standing unipedal test is consistent with the known effects of shortening velocity on muscle contractile force. The usual difference between isometric strength and $60 \mathrm{deg} / \mathrm{sec}$ peak isokinetic strength ranges from $10 \%$ to $30 \%$ for the thigh muscles ${ }^{19,20,34}$ and $34 \%$ to $47 \%$ for the ankle muscles. ${ }^{31}$

The three quarter-top shoe did not significantly augment active resistance to eversion moments at any angle of plantar flexion. Fortunately, eversion ankle sprains are much less common than inversion sprains. The lower levels of active resistance generated with the three quarter-top shoes at the neutral position were unexpected and a factor to be considered in an individual with a history of eversion sprains.

Because of the frequency of ankle injuries in running, jumping, turning, and twisting sports, ${ }^{8,9,15,23}$ several methods of ankle protection have evolved, including high-top shoes, taping, ${ }^{5}$ and orthoses. ${ }^{2,6}$ In fact, ankle taping or wrapping has become a medical requirement in many competitive contact and jumping sports. ${ }^{12}$ These aids appear to provide ankle protection by limiting the extremes of motion, at which ligament injuries occur. ${ }^{7,24,26}$ Interestingly, there is some evidence that taping may also augment muscle function. ${ }^{18}$ Unfortunately, tape loosening can occur during athletic activity, which may decrease its protective function over time. ${ }^{13,22,27,29}$ Because daily taping can be quite irritating to the skin, nonadherent forms of ankle support have been developed. Lace-up orthoses have become popular in many sports because they are easy to apply and can be retightened when they loosen. They are reusable and do not require trained athletic personnel for their 
application. Their advantages have been outlined in several investigations. ${ }^{14,28}$

Garrick and Requa ${ }^{10}$ studied 2562 basketball player games and demonstrated the lowest ankle injury rates among players with high-top shoes and taped ankles, with rates of 6.5 sprains per 1000 player games. The highest rate of injury was seen among players with low-top shoes and no tape: 33.4 sprains per 1000 player games. When no tape was used in previously injured ankles, the high-top shoes were minimally safer than low-top shoes: 30.4 compared with 33.4 sprains per 1000 player games. Interestingly, in players with a history of ankle sprains, those wearing hightop shoes had half the injury rate that those wearing lowtop shoes did. Barrett et al., ${ }^{1}$ in a study of 622 basketball players observed over the course of a year, noted no difference in injury rates among players wearing high-top inflated, high-top, and low-top shoes. The lack of injury rate difference in the more recent study may be attributable to the low number (15) of ankle sprains reported. ${ }^{1}$

Most ankle sprains are thought to occur with the foot plantar flexed, inverted, and internally rotated, ${ }^{8}$ a position in which the anterior talofibular ligament is subject to the greatest degree of strain. ${ }^{4}$ Although we did not test this directly, the higher-top shoe may improve resistance to an inversion rotation by limiting the degree of passive inversion, thereby stiffening the ankle-foot complex. Although this explanation is quite plausible, other possibilities include improved resistance to passive internal rotation or plantar flexion. Karlsson et al. ${ }^{18}$ have shown that taping can improve the muscle reaction time of the peroneus brevis muscle of unstable ankles during gait. This muscle augmentation possibility deserves further consideration.

\section{CONCLUSIONS}

1. The three quarter-top basketball shoe that was tested allowed participants to actively resist significantly larger external moments at $0^{\circ}$ and $16^{\circ}$ of ankle plantar flexion than the low-top basketball shoes.

2. The inversion moments that individuals were able to actively resist were the greatest at $32^{\circ}$ of ankle plantar flexion and decreased with decreasing ankle plantar flexion. Significant differences were observed between $0^{\circ}$ and $16^{\circ}$ and between $0^{\circ}$ and $32^{\circ}$ of ankle plantar flexion.

3. The eversion moments that individuals were able to actively resist were the greatest at $0^{\circ}$ of ankle plantar flexion and decreased with increasing ankle plantar flexion. Significant differences were observed between $0^{\circ}$ and $32^{\circ}$ of ankle plantar flexion.

4. There were no significant correlations among unipedal ankle strength, isokinetic ankle strength, isokinetic time to peak torque, physical activity level, and calf circumference.

\section{ACKNOWLEDGMENTS}

This study was supported by PHS grant PO1 AG10542 and The University of Michigan Medical School's Student Biomedical Research Program.

\section{REFERENCES}

1. Barrett JR, Tanji JL, Drake C, et al: High-versus low-top shoes for the prevention of ankle sprains in basketball players. Am J Sports Med 21: 582-585, 1993

2. Burks RT, Bean BG, Marcus $R$, et al: Analysis of athletic performance with prophylactic ankle devices. Am J Sports Med 19: 104-106, 1991

3. Chen J, Siegler S, Schneck CD: The three-dimensional kinematics and flexibility characteristics of the human ankle and subtalar joint. Part II: Flexibility characteristics. J Biomech Eng 110: 374-385, 1988

4. Colville MR, Marder RA, Boyle JJ, et al: Strain measurement in lateral ankle ligaments. Am J Sports Med 18: 196-200, 1990

5. Firer P: Effectiveness of taping for the prevention of ankle ligament sprains. Br J Sports Med 24: 47-50, 1990

6. Fridén $\mathrm{T}$, Zätterström R, Lindstrand A, et al: A stabilometric technique for evaluation of lower limb instabilities. Am J Sports Med 17: 118-122, 1989

7. Fumich RM, Ellison AE, Guerin GJ, et al: The measured effect of taping on combined foot and ankle motion before and after exercise. Am $J$ Sports Med 9: 165-170, 1981

8. Garrick JG: The frequency of injury, mechanism of injury, and epidemiology of ankle sprains. Am J Sports Med 5: 241-242, 1977

9. Garrick JG, Requa RK: The epidemiology of foot and ankle injuries in sports. Clin Sports Med 7: 29-36, 1988

10. Garrick JG, Requa RK: Role of external support in the prevention of ankle sprains. Med Sci Sports 5: 200-203, 1973

11. Gilsing $M$, Vanden Bosch $C$, Lee $S G$, et al: Association of age with the threshold for detecting ankle inversion and eversion in upright stance. Age Aging 24: 58-66, 1995

12. Glick JM, Gordon RB, Nishimoto D: The prevention and treatment of ankle injuries. Am J Sports Med 4: 136-141, 1976

13. Greene TA, Hillman SK: Comparison of support provided by a semirigid orthosis and adhesive ankle taping before, during, and after exercise. Am J Sports Med 18: 498-506, 1990

14. Gross MT, Bradshaw MK, Ventry LC, et al: Comparison of support provided by ankle taping and semirigid orthosis. $J$ Orthop Sports Phys Ther 9:33-39, 1987

15. Jackson DW, Ashley RL, Powell JW: Ankle sprains in young athletes. Clin Orthop 101: 201-215, 1974

16. Johnson EE, Markolf $\mathrm{KL}$ : The contribution of the anterior talofibular ligament to ankle laxity. J Bone Joint Surg 65A: 81-88, 1983

17. Johnson $M B$, Johnson $C L$ : Electromyographic response of peroneal muscles in surgical and nonsurgical injured ankles during sudden inversion. J Othop Sports Phys Ther 18: 497-501, 1993

18. Karlsson J, Andreasson GO: The effect of external ankle support in chronic lateral ankle joint instability. Am J Sports Med 20: 257-261, 1992

19. Knapik JJ, Ramos MU: Isokinetic and isometric torque relationships in the human body. Arch Phys Med Rehabil 61(2): 64-67, 1980

20. Knapik JJ, Wright JE, Mawdsley RH, et al: Isometric, isotonic, and isokinetic torque variations in four muscle groups through a range of motion. Arch Phys Med Rehabil 64(2): 77-80, 1993

21. Koradsen L, Ravn JB: Ankle instability caused by prolonged peroneal reaction time. Acta Orthop Scand 61: 388-390, 1990

22. Laughman RK, Carr TA, Chao EY, ef al: Three-dimensional kinematics of the taped ankle before and after exercise. Am J Sports Med 8: 425-431, 1980

23. Mack RP: Ankle injuries in athletics. Clin Sports Med 1: 71-84, 1982

24. McCluskey GM, Blackburn TA, Lewis T: Prevention of ankle sprains. Am $\checkmark$ Sports Med 4: 151-157, 1976

25. Mizrahi J, Ramot $Y$, Susak $Z$ : The dynamics of the subtalar joint in sudden inversion of the foot. J Biomech Eng 112: 9-14, 1990

26. Morris $\mathrm{HH}$, Musnicki III $\mathrm{W}$ : The effect of taping on ankle mobility following moderate exercise. J Sports Med Phys Fitness 23: 422-426, 1983

27. Rarick GL, Bigley G, Karst R, et al: The measurable support of the ankle joint by conventional methods of taping. J Bone Joint Surg 44A: 1183-1190, 1962

28. Rovere GD, Clarke TJ, Yates CS, et al: Retrospective comparison of taping and ankle stabilizers in preventing ankle injuries. Am J Sports Med 16: $228-233,1988$

29. Shapiro MS, Kabo JM, Mitchell PW, et al: Ankle sprain prophylaxis: An analysis of the stabilizing effects of braces and tape. Am J Sports Med 22: $78-82,1994$

30. Sprigings EJ, Pelton JD, Brandell BR: An EMG analysis of the effectiveness of external ankle support during sudden ankle inversion. Can J App/ Sport Sci $6: 72-75,1981$

31. Thelen DG, Schultz AB, Alexander NB, et al: Effects of age and aging on rapid ankle torque development. $J$ Gerentol Med Sci, in press, 1995

32. Videla DG, Ashton-Milier JA: Use of unipedal stance to measure ankle isometric strength and endurance in the sagittal and frontal planes. $J$ Biomechanics, in press, 1995

33. Winter DA: The Biomechanics And Motor Control Of Human Gait: Normal, Elderly And Pathology. Second Edition. Waterloo, Ontario, University of Waterloo Press, 1991

34. Yoon TS, Park DS, Kang SW, et al: Isometric and isokinetic torque curves at the knee joint. Yonsei Med J 32(1): 33-43, 1991 